\title{
A High Voltage Mg-ion Battery Cathode via a Solid Solution Cr-Mn Spinel Oxide
}

Bob Jin Kwon ${ }^{1,2, *}$, Liang Yin ${ }^{2,3}$, Haesun Park ${ }^{2,4}$, Prakash Parajuli²,5, Khagesh Kumar ${ }^{2,6}$, Sanghyeon Kim ${ }^{1,2}$, Mengxi Yang ${ }^{1,2}$, Megan Murphy ${ }^{2,6}$, Peter Zapol ${ }^{2,4}$, Chen Liao ${ }^{1,2}$, Timothy T. Fister ${ }^{1,2}$, Robert F. Klie ${ }^{2,5}$, Jordi Cabana ${ }^{2,6}$, John T. Vaughey ${ }^{1,2}$, Saul H. Lapidus ${ }^{2,3}$, and Baris $\operatorname{Key}^{1,2, *}$

${ }^{1}$ Chemical Sciences and Engineering Division Argonne National Laboratory, Lemont, IL 60439, United States

${ }^{2}$ Joint Center for Energy Storage Research, Argonne National Laboratory, Lemont, IL 60439, United States

${ }^{3}$ X-ray Science Division, Advanced Photon Source, Argonne National Laboratory, Lemont, IL, 60439, United States

${ }^{4}$ Materials Science Division, Argonne National Laboratory, Lemont, IL, 60439, United States ${ }^{5}$ Department of Physics, University of Illinois at Chicago, Chicago, IL 60607, United States ${ }^{6}$ Department of Chemistry, University of Illinois at Chicago, Chicago, IL 60607, United States

\section{Corresponding Author}

*E-mail: bkwon@anl.gov, bkey@anl.gov 


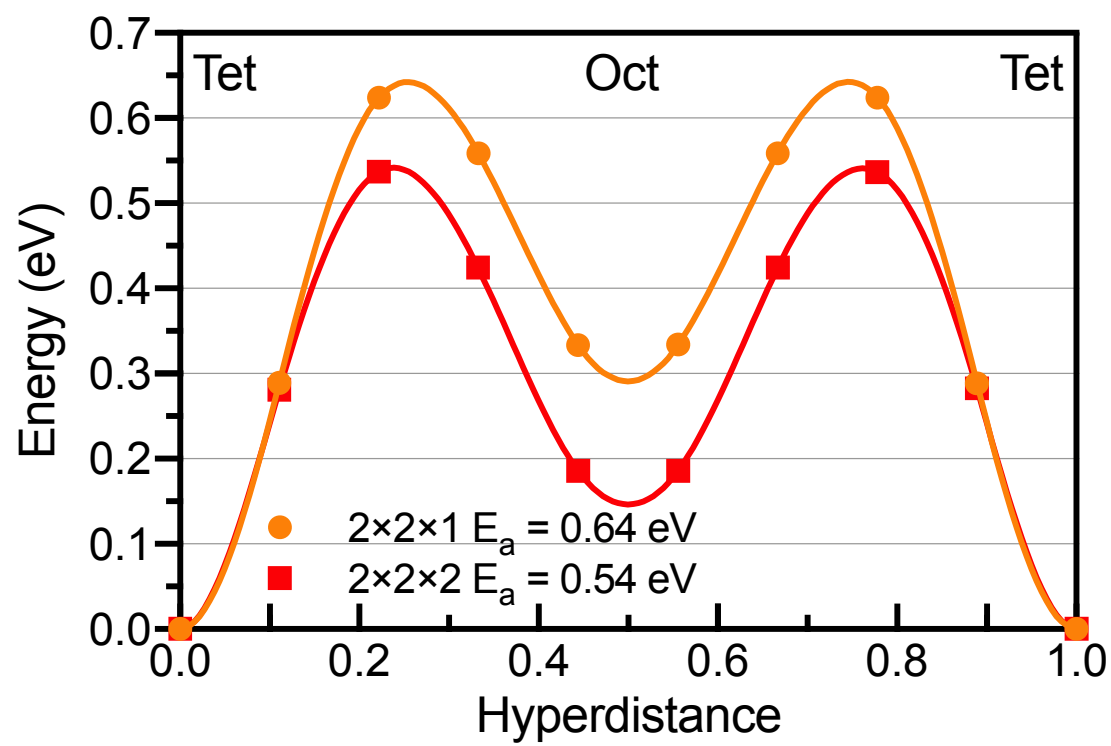

Figure S1. Minimum energy pathways for $\mathrm{Mg}^{2+}$ migration in $\mathrm{MgCr}_{2} \mathrm{O}_{4}$ spinel at the dilute vacancy limit in two different scales of unit cells. 

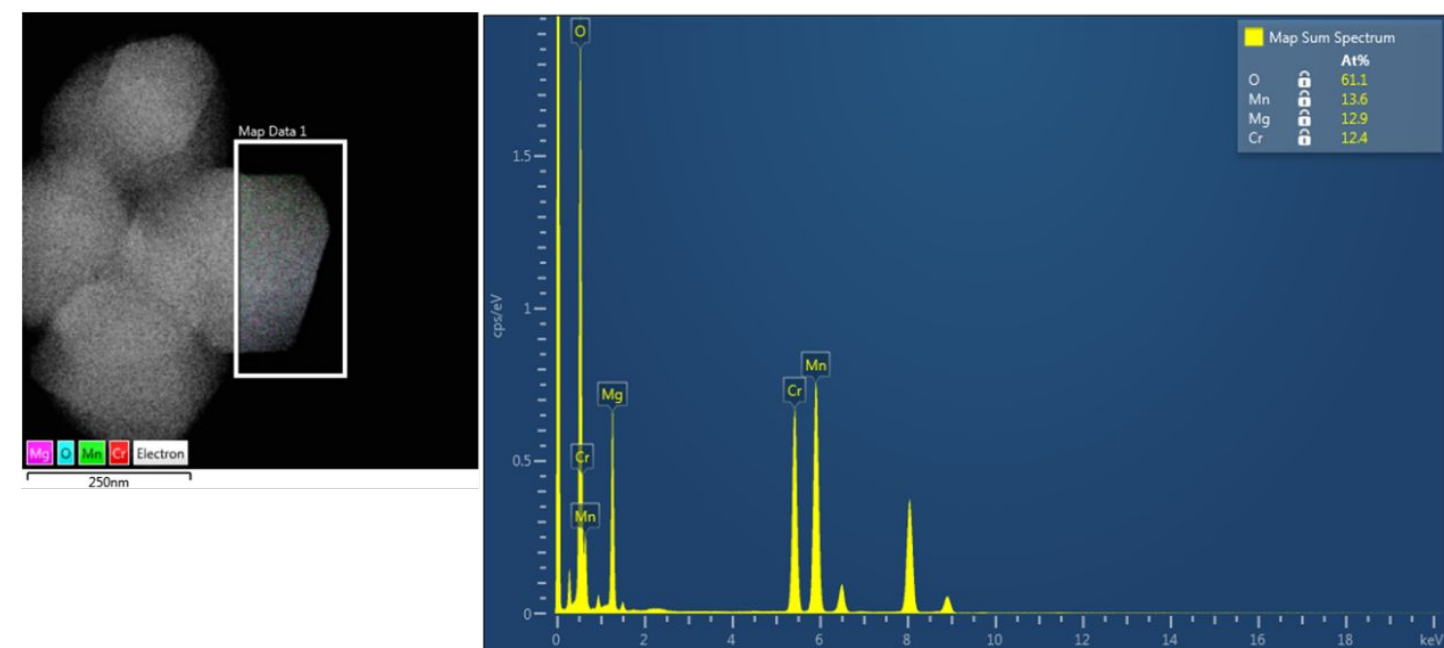

Figure S2. (a) EDX spectrum of pristine $\mathrm{MgCrMnO}_{4}$ nanocrystals. 


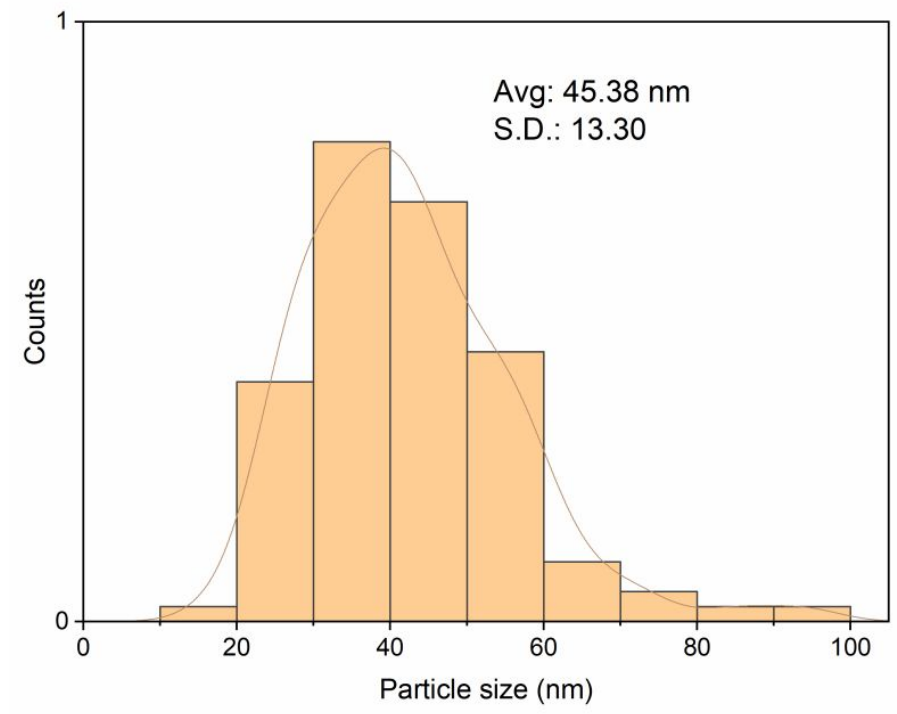

Figure S3. Particle size distribution of $\mathrm{MgCrMnO}_{4}$ nanocrystals synthesized at $700{ }^{\circ} \mathrm{C}$. The values were estimated by measuring more than 100 particles on the microscopic images. 


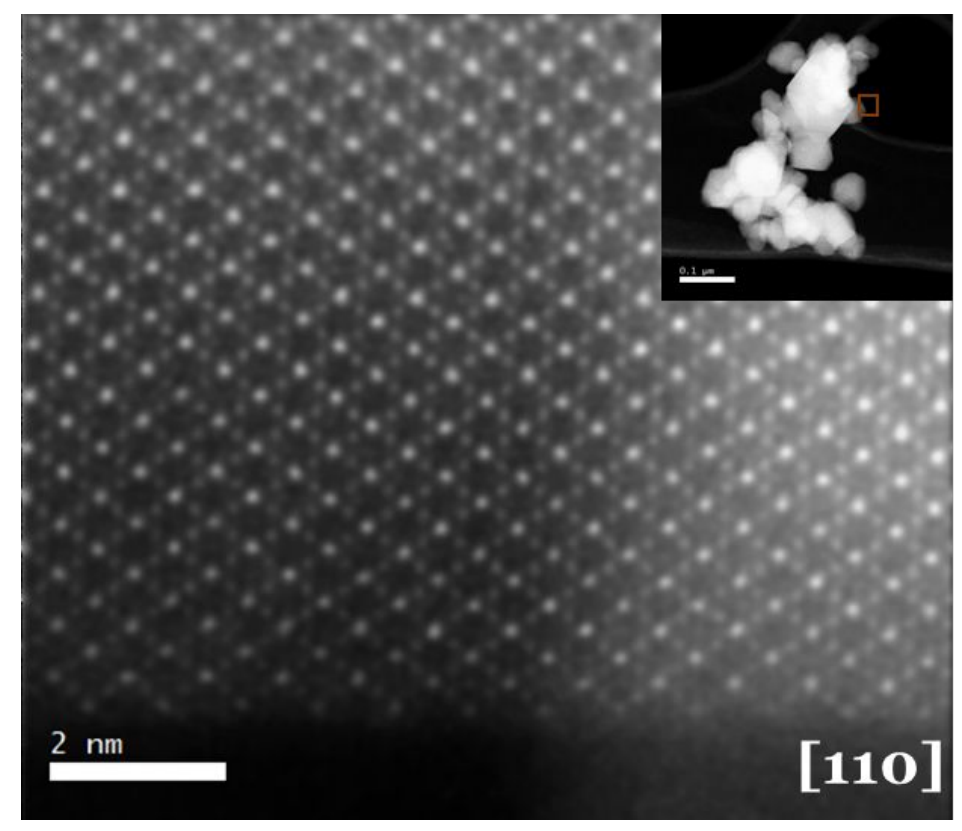

Figure S4. HAADF images of pristine $\mathrm{MgCrMnO}_{4}$ at the bulk and surface along with a [110] zone axis. The insets with $100 \mathrm{~nm}$ of a scale bar indicated the selected areas for the images. 


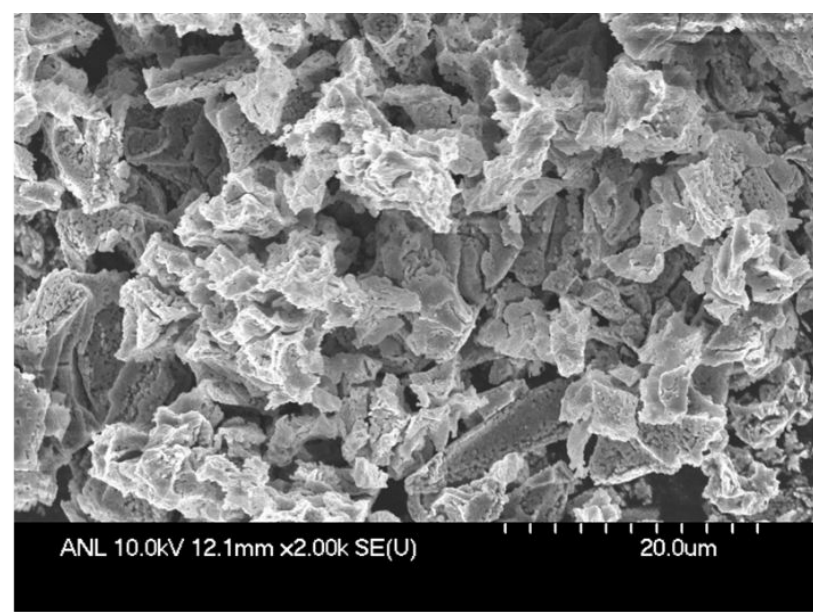

Min. $\mathrm{Mg} /(\mathrm{Cr}+\mathrm{Mn})=\sim 0.38$

Max. $\mathrm{Mg} /(\mathrm{Cr}+\mathrm{Mn})=\sim 0.32$

\begin{tabular}{|c|c|c|c|c|c|c|c|c|c|c|c|}
\hline Element & At. No. & Netto & $\begin{array}{c}\text { Mass } \\
{[\%]}\end{array}$ & $\begin{array}{c}\text { Mass Norm. } \\
{[\%]}\end{array}$ & $\begin{array}{l}\text { Atom } \\
{[\%]}\end{array}$ & Element & At. No. & Netto & $\begin{array}{l}\text { Mass } \\
{[\%]}\end{array}$ & $\begin{array}{c}\text { Mass Norm. } \\
{[\%]}\end{array}$ & $\begin{array}{l}\text { Atom } \\
{[\%]}\end{array}$ \\
\hline Carbon & & 329258 & 57.58 & 49.84 & 65.61 & Carbon & & 295410 & 53.66 & 50.94 & 67.56 \\
\hline Oxyg & 8 & 50805 & 10.68 & 9.24 & 9.13 & Oxygen & 8 & 29717 & 6.63 & 6.29 & 6.27 \\
\hline Fluorine & & 142365 & 26.47 & 22.91 & 19.07 & Fluorine & & 124987 & 24.56 & 23.31 & 19.54 \\
\hline Magnesium & 12 & 52938 & 2.97 & 2.57 & 1.67 & Magnesium & 12 & 38241 & 2.51 & 2.38 & 1.56 \\
\hline Chromium & 24 & 65354 & 7.71 & 6.67 & 2.03 & Chromium & 24 & 64627 & 7.91 & 7.51 & 2.30 \\
\hline \multirow[t]{2}{*}{ Manganese } & 25 & 64411 & 9.71 & 8.40 & 2.42 & Manganese & 25 & 63881 & 10.07 & 9.56 & 2.77 \\
\hline & & \multicolumn{2}{|c|}{ Sum 115.53} & \multicolumn{2}{|c|}{100.00100 .00} & & & \multicolumn{2}{|c|}{ Sum 105.34} & \multicolumn{2}{|c|}{100.00100 .00} \\
\hline
\end{tabular}

Figure S5. SEM-EDX of charged $\mathrm{MgCrMnO}_{4}$ electrode prepared in a coin-cell at $95{ }^{\circ} \mathrm{C}$ paired with a carbon counter electrode. The electrodes were washed multiple times by Acetonitrile. 


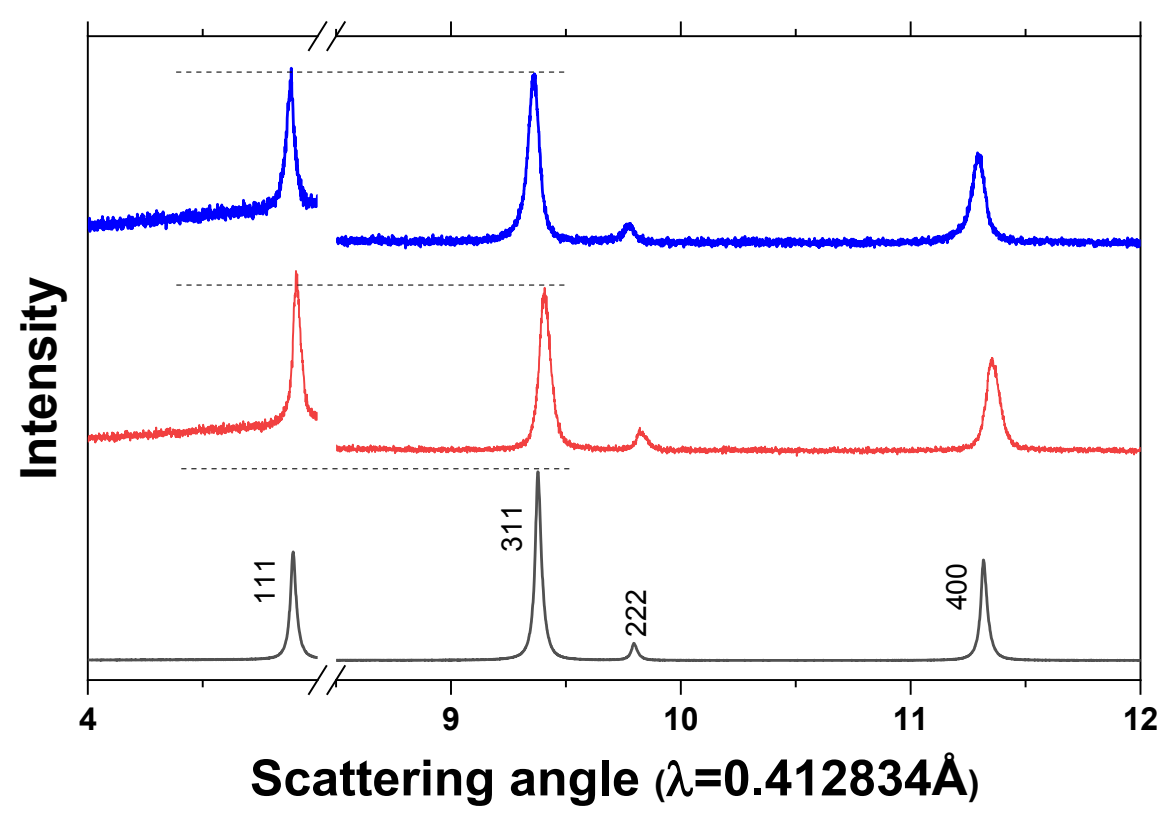

Figure S6. Synchrotron XRD patterns of pristine (black), charged (red), and discharged $\mathrm{MgCrMnO}_{4}$ (blue) for comparison of the intensity ratio between (111) and (311) reflections. 

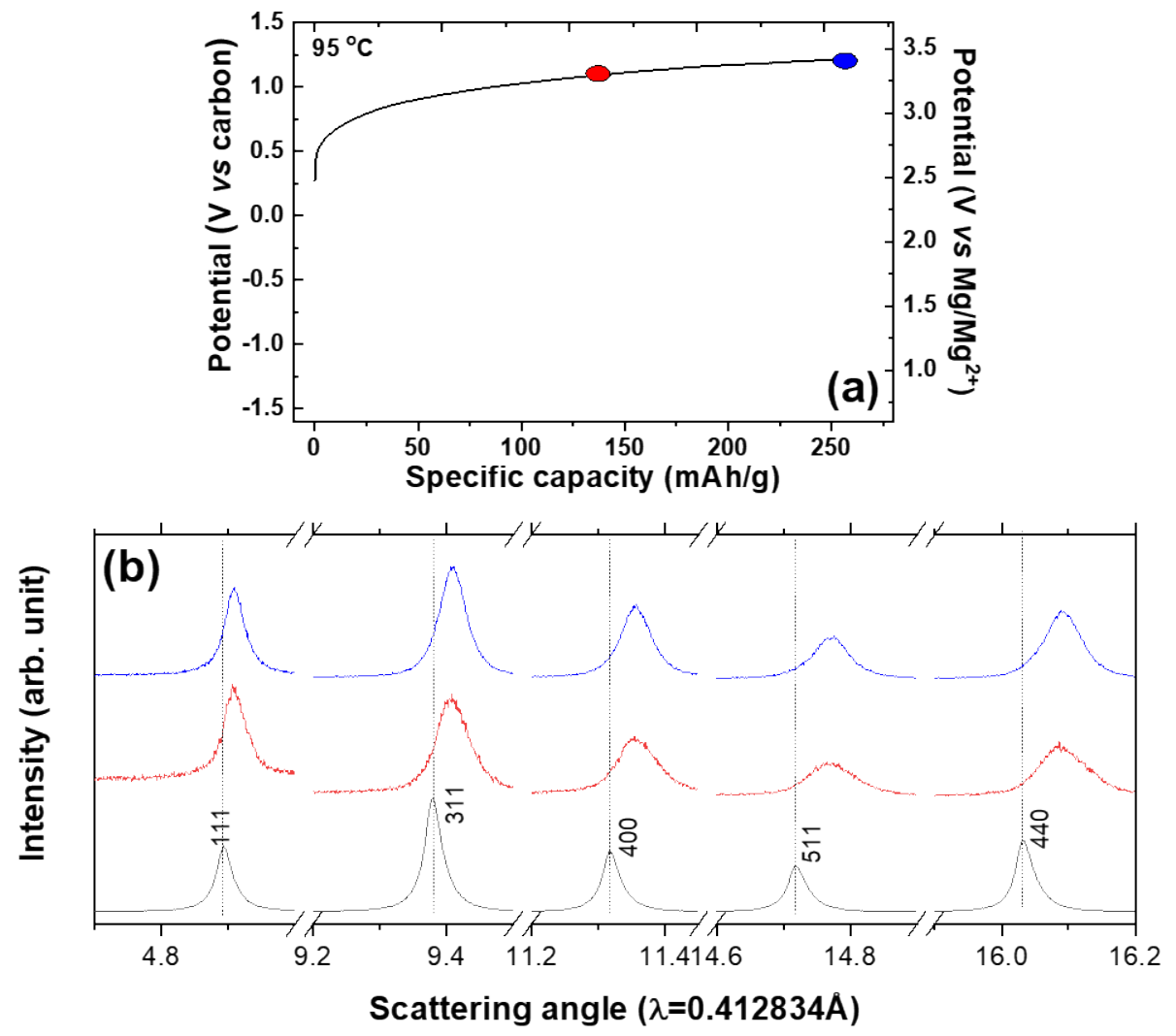

Figure S7. (a) Potential versus capacity profile of $\mathrm{MgCrMnO}_{4}$ paired with a carbon counter electrode at $95{ }^{\circ} \mathrm{C}$. The cell was charged to $\sim 1.22 \mathrm{~V}$ ( $v s$ carbon) where $\sim 255 \mathrm{mAh} / \mathrm{g}$ capacity was delivered. (b) Synchrotron XRD patterns of pristine (black) and ex-situ electrodes (red and blue) at different states of charges as indicated in the electrochemical curve. 


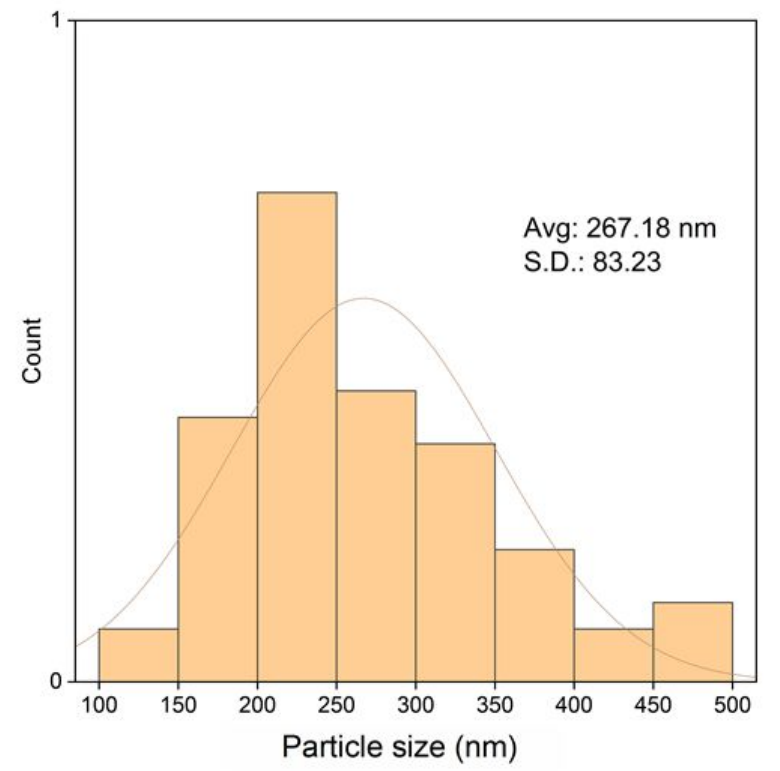

Figure S8. Particle size distribution of $\mathrm{MgCrMnO}_{4}$ nanocrystals synthesized at $950{ }^{\circ} \mathrm{C}$. The values were estimated by measuring more than 100 particles on the microscopic images. 

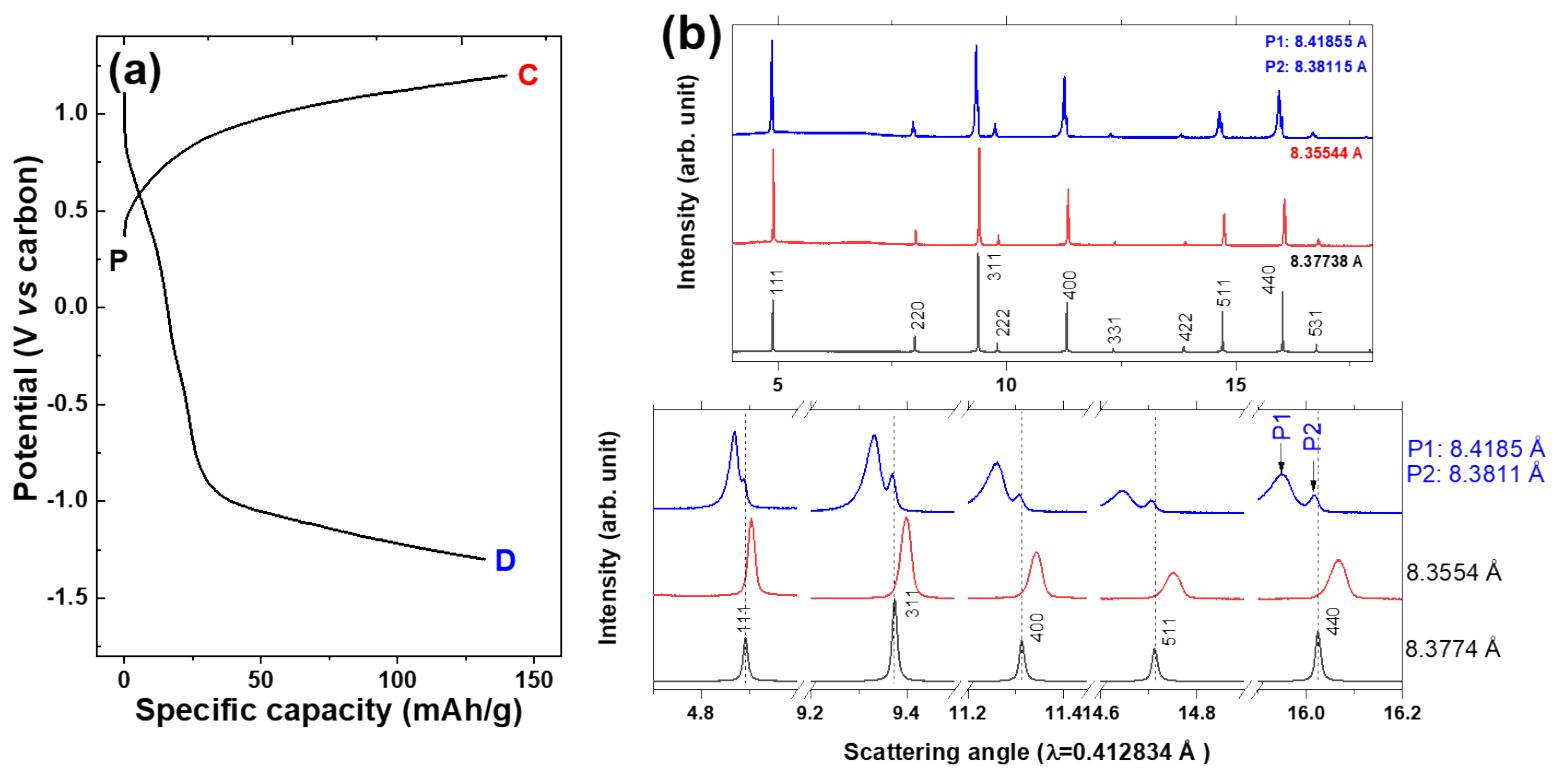

Figure S9. (a) Potential versus capacity profile of $\mathrm{MgCrMnO}_{4}$ synthesized at $950{ }^{\circ} \mathrm{C}$ paired with a carbon counter electrode at $95{ }^{\circ} \mathrm{C}$. (b) Synchrotron XRD patterns of pristine (black), charged (red), and discharged $\mathrm{MgCrMnO}_{4}$ (blue) synthesized at $950{ }^{\circ} \mathrm{C}$. The values indicated lattice parameters of the cubic spinels at different states of charges. 

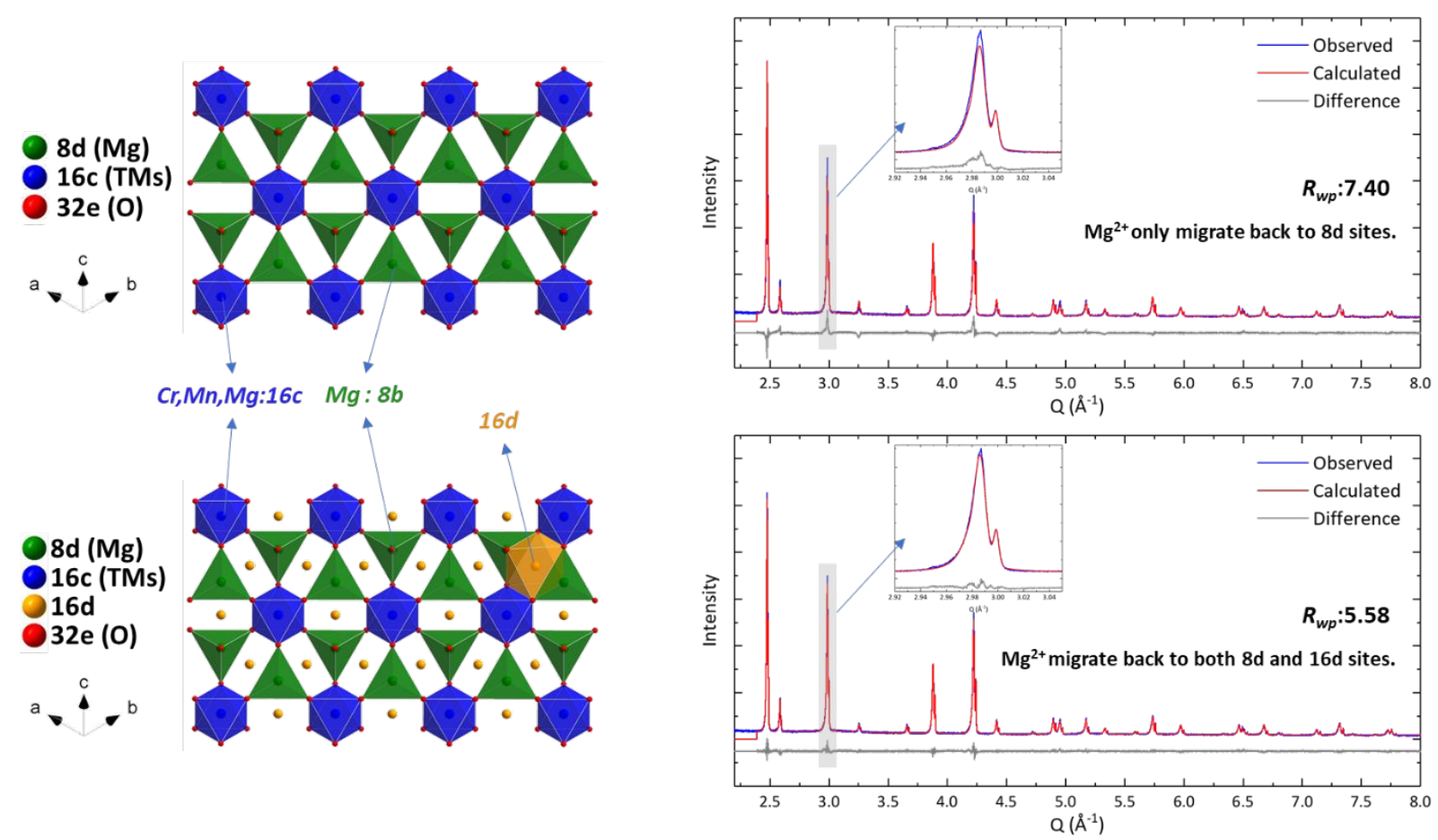

Figure S10. Schematic description of the proposed mechanism for $\mathrm{Mg}^{2+}$ intercalation into the spinel and the refinement results for discharged $\mathrm{MgCrMnO}_{4}$. 


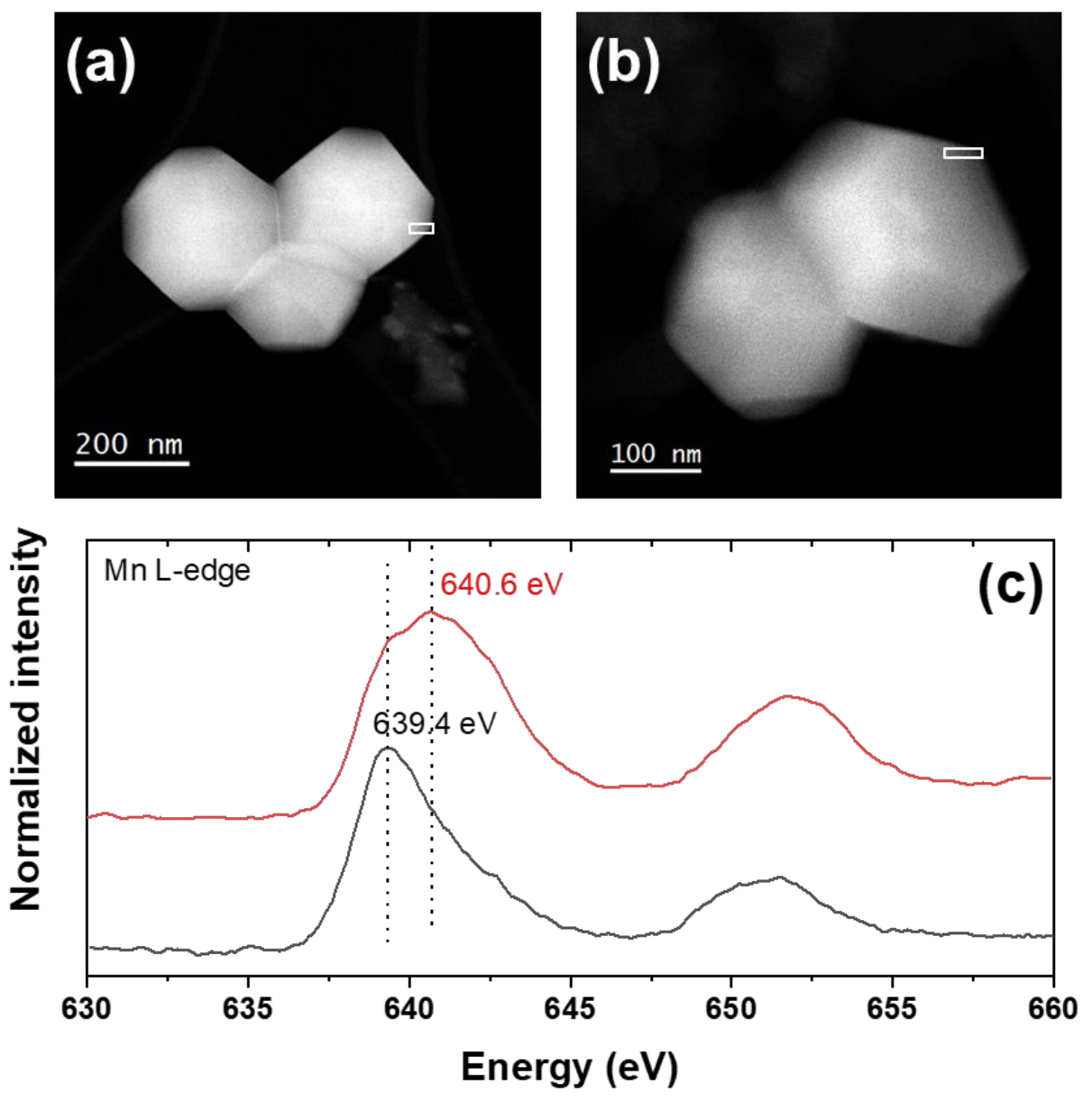

Figure S11. LAADF images of (a) pristine and (b) demagnesiated $\mathrm{MgCrMnO}_{4}$ nanocrystals. The rectangle in the images indicated the actual areas for EELS measurement. (c) Mn L-edge spectra of pristine (black) and charged $\mathrm{MgCrMnO}_{4}$ (red) collected from the marked areas. 


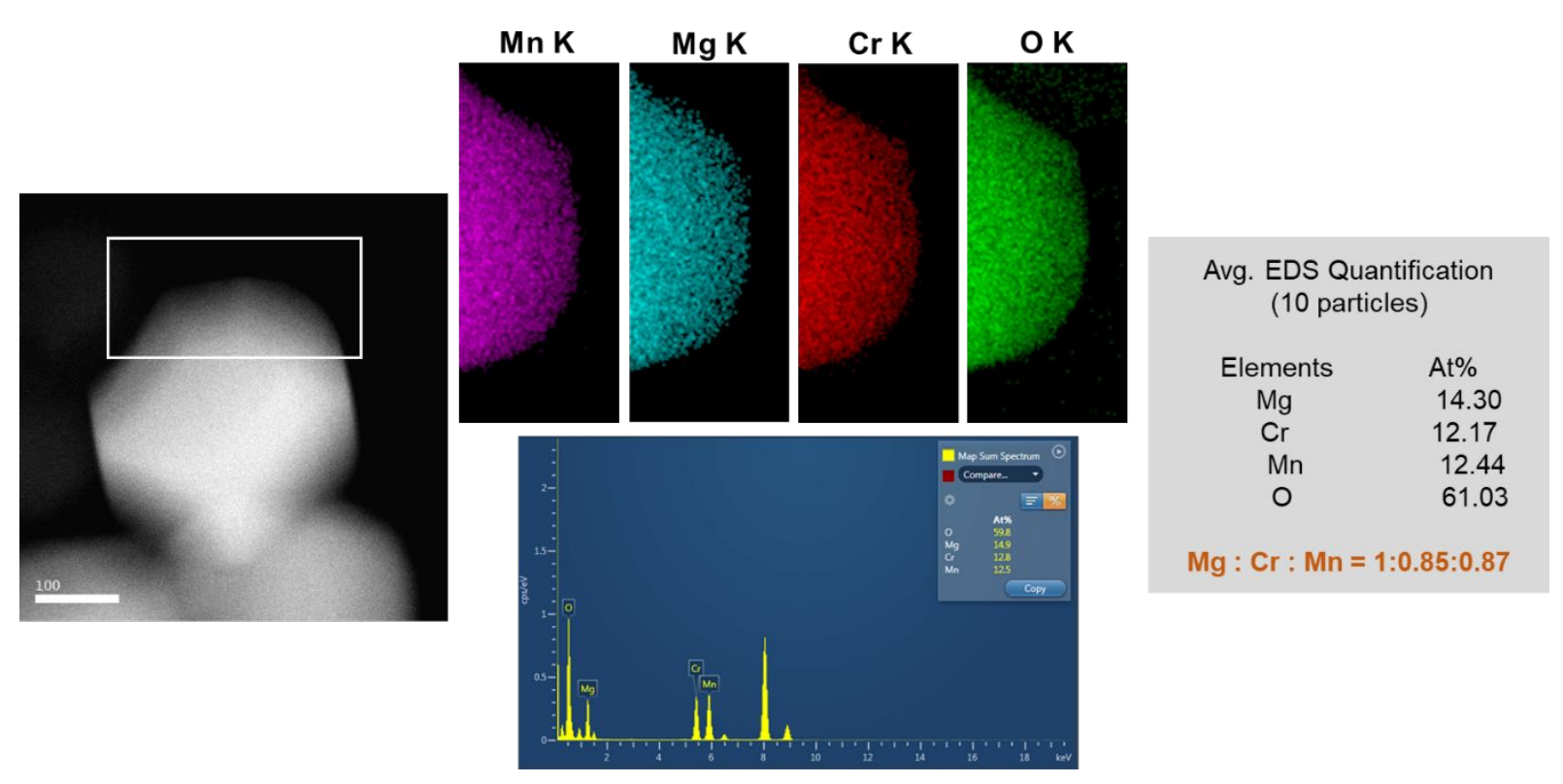

\begin{tabular}{|c|c|}
\hline \multicolumn{2}{|c|}{ Discharged (At\%) } \\
\hline Avg. & S.D. \\
\hline Mg: 14.30 & 0.760 \\
\hline Cr: 12.17 & 0.848 \\
\hline Mn: 12.44 & 0.653 \\
\hline O: 61.03 & 1.587 \\
\hline
\end{tabular}

Figure S12. EDX mapping of discharged $\mathrm{MgCrMnO}_{4}$ electrode and the corresponding spectra. The average atomic ratio and standard deviation were calculated by measuring 10 different spots. 


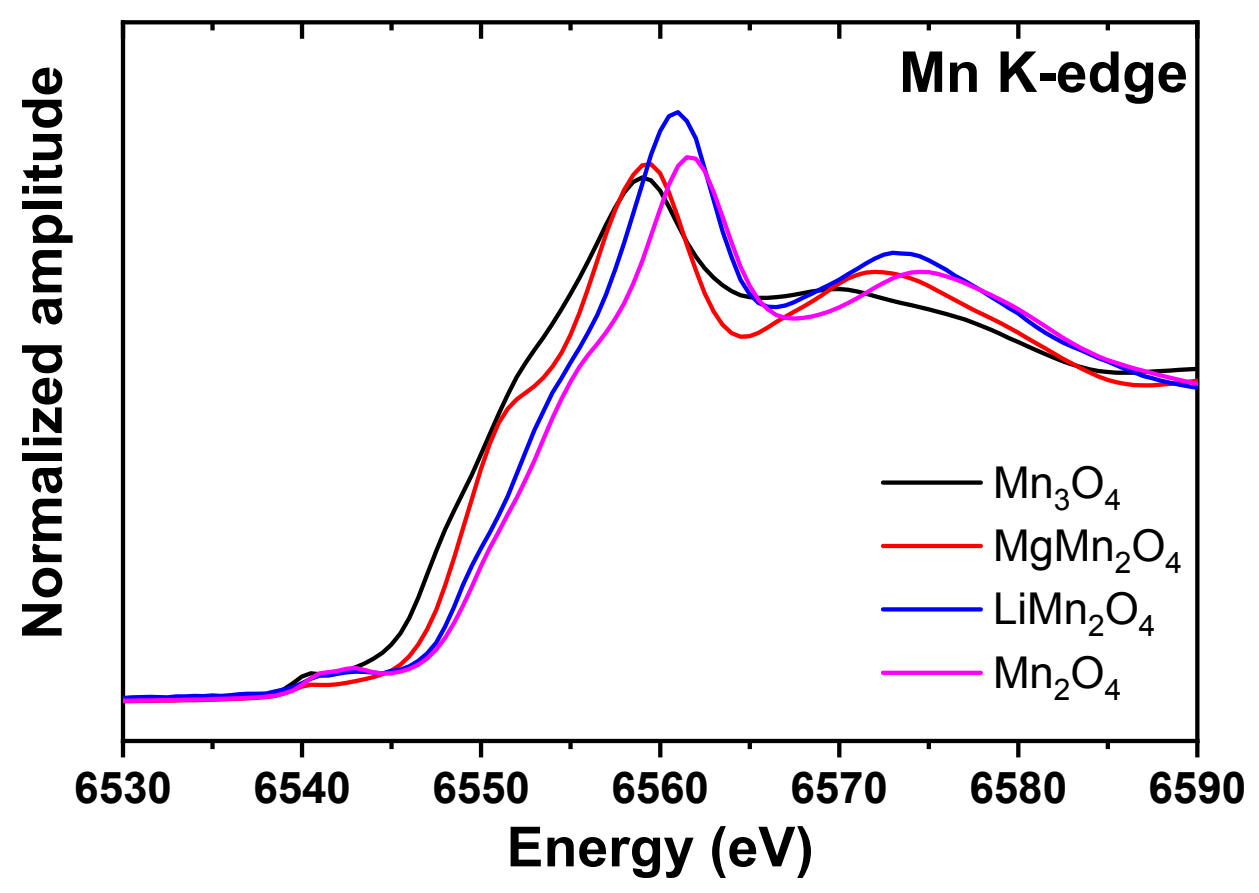

Figure S13. Mn K-edge spectra of Mn-spinel standards. 

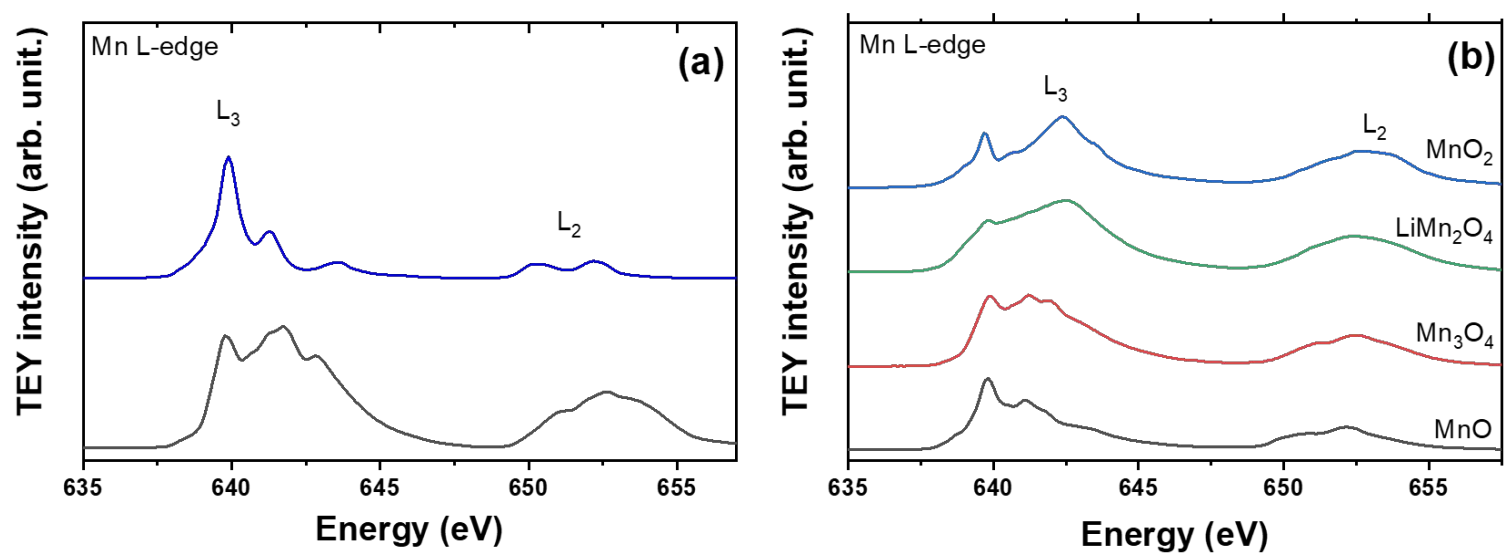

Figure S14. (a) Mn L-edge spectra of pristine (black) and discharged (blue) $\mathrm{MgCrMnO}_{4}$. (b)

Mn L-edge spectra of standard Mn-oxides. Both spectra were collected in a total electron yielding (TEY) mode. 


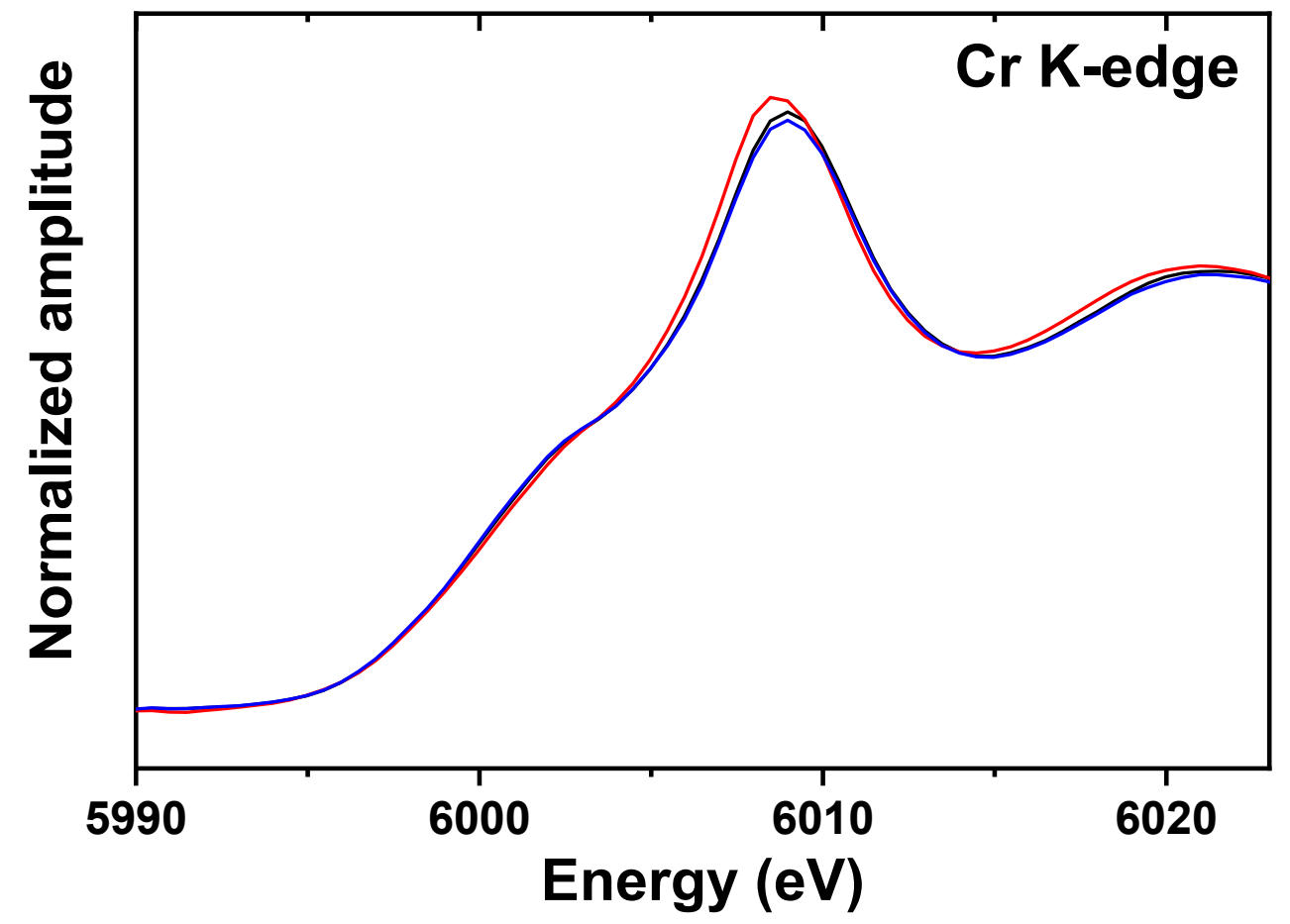

Figure S15. Cr K-edge spectra of pristine (black), charged (red) and discharged (blue) $\mathrm{MgCrMnO}_{4}$ prepared in a coin-cell at $95^{\circ} \mathrm{C}$. 


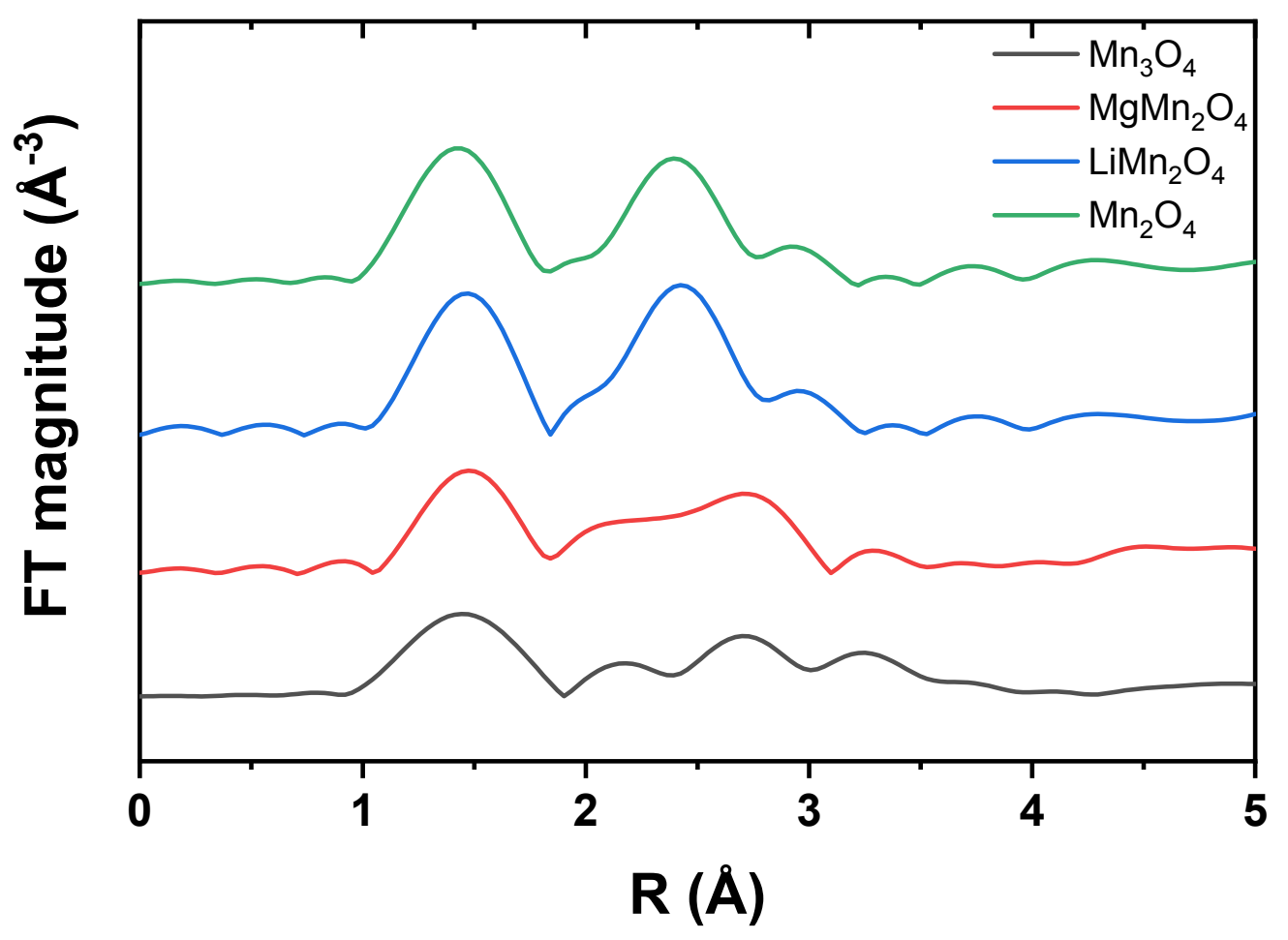

Figure S16. Mn K-edge extended X-ray absorption fine structure (EXAFS) of standard Mn spinels. 


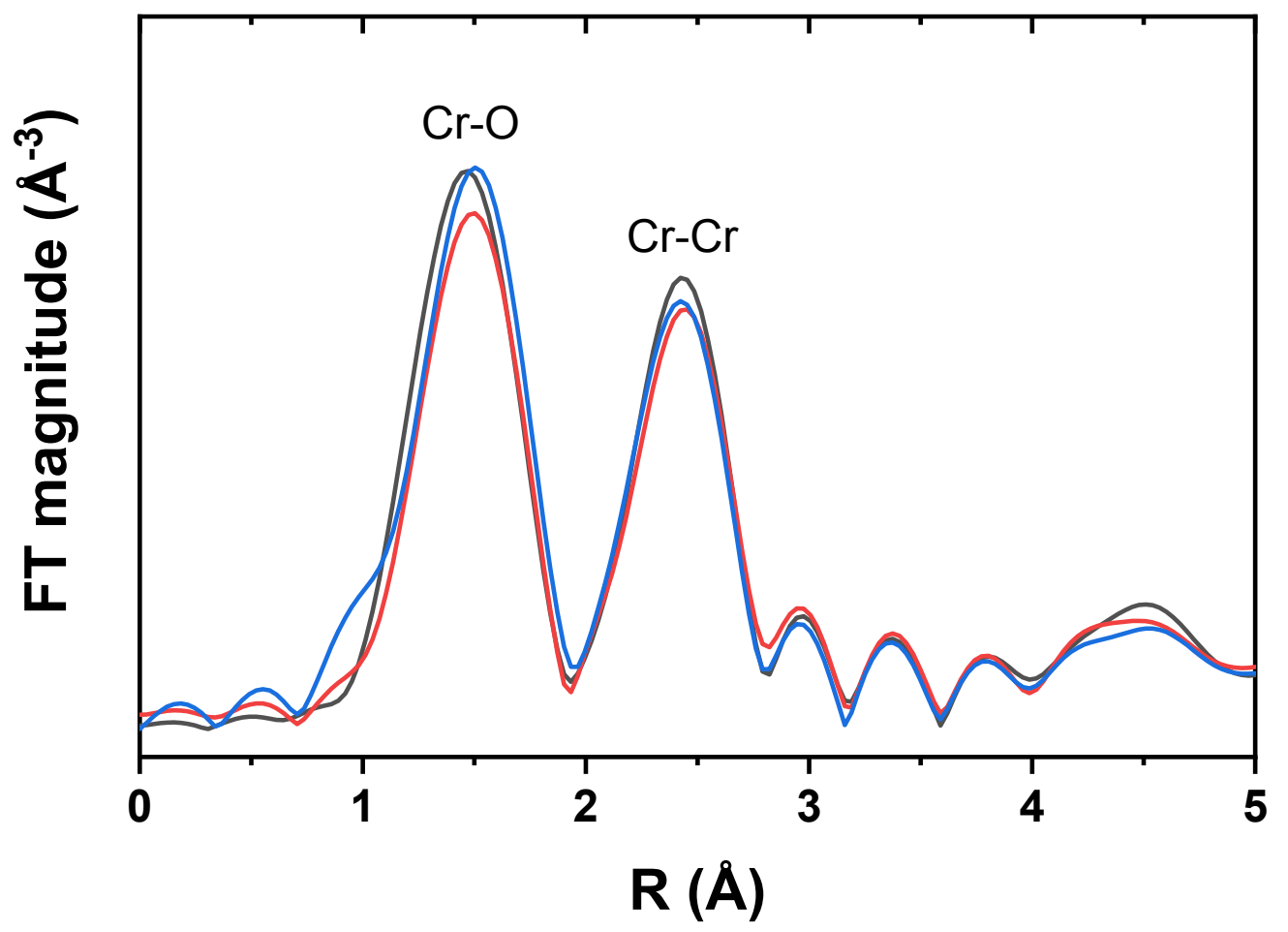

Figure S17. Cr K-edge extended X-ray absorption fine structure (EXAFS) of pristine (black), charged (red) and discharged (blue) $\mathrm{MgCrMnO}_{4}$. 


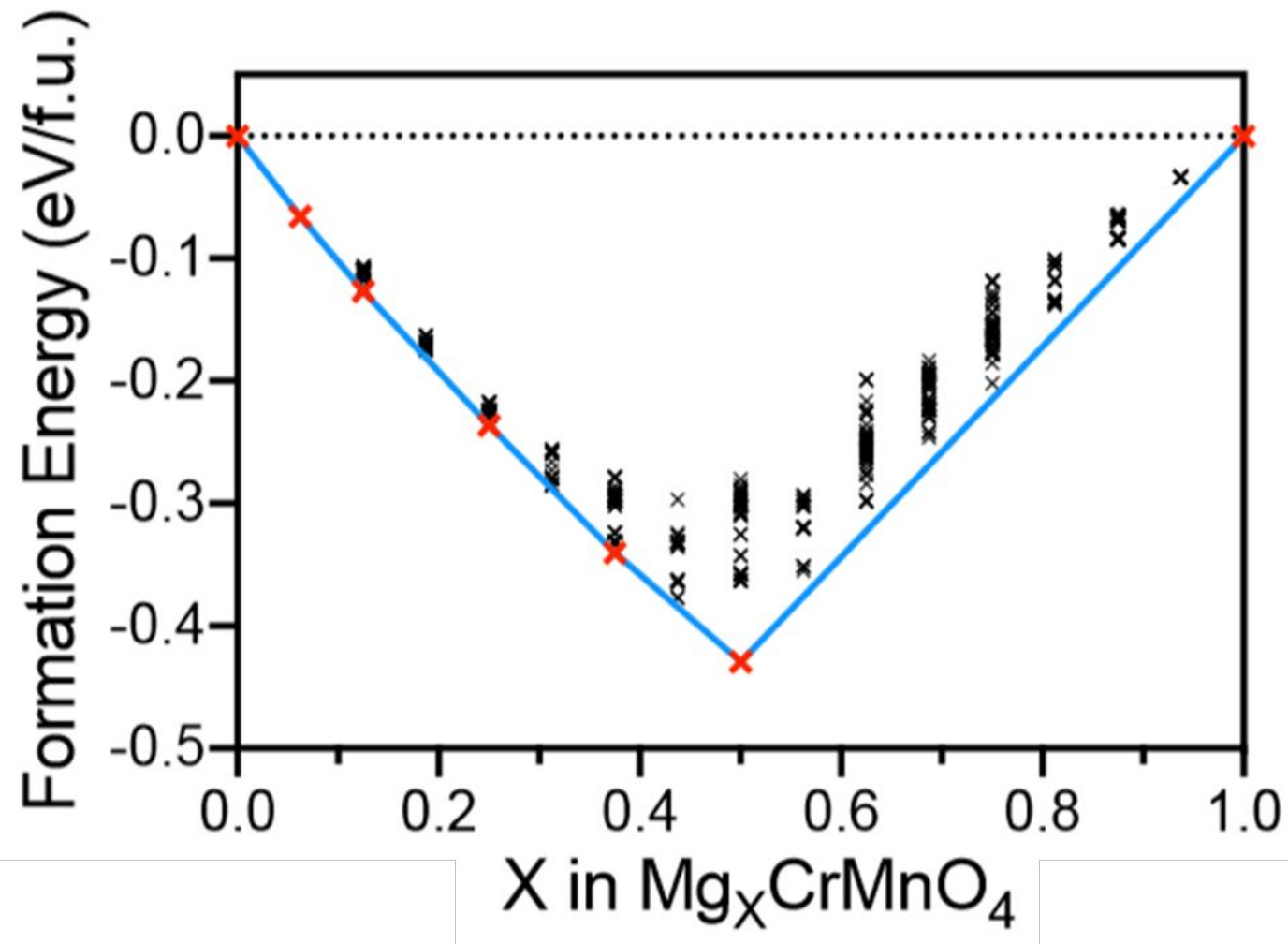

Figure S18. Ground state hull of the $\mathrm{Mg}_{\mathrm{x}} \mathrm{CrMnO}_{4}$ spinel system $(0 \leq \mathrm{x} \leq 1)$ with the zero of formation energy calibrated to the fully magnesiated $\mathrm{MgCrMnO}_{4}$ and empty $\mathrm{CrMnO}_{4}$ spinel configurations. 

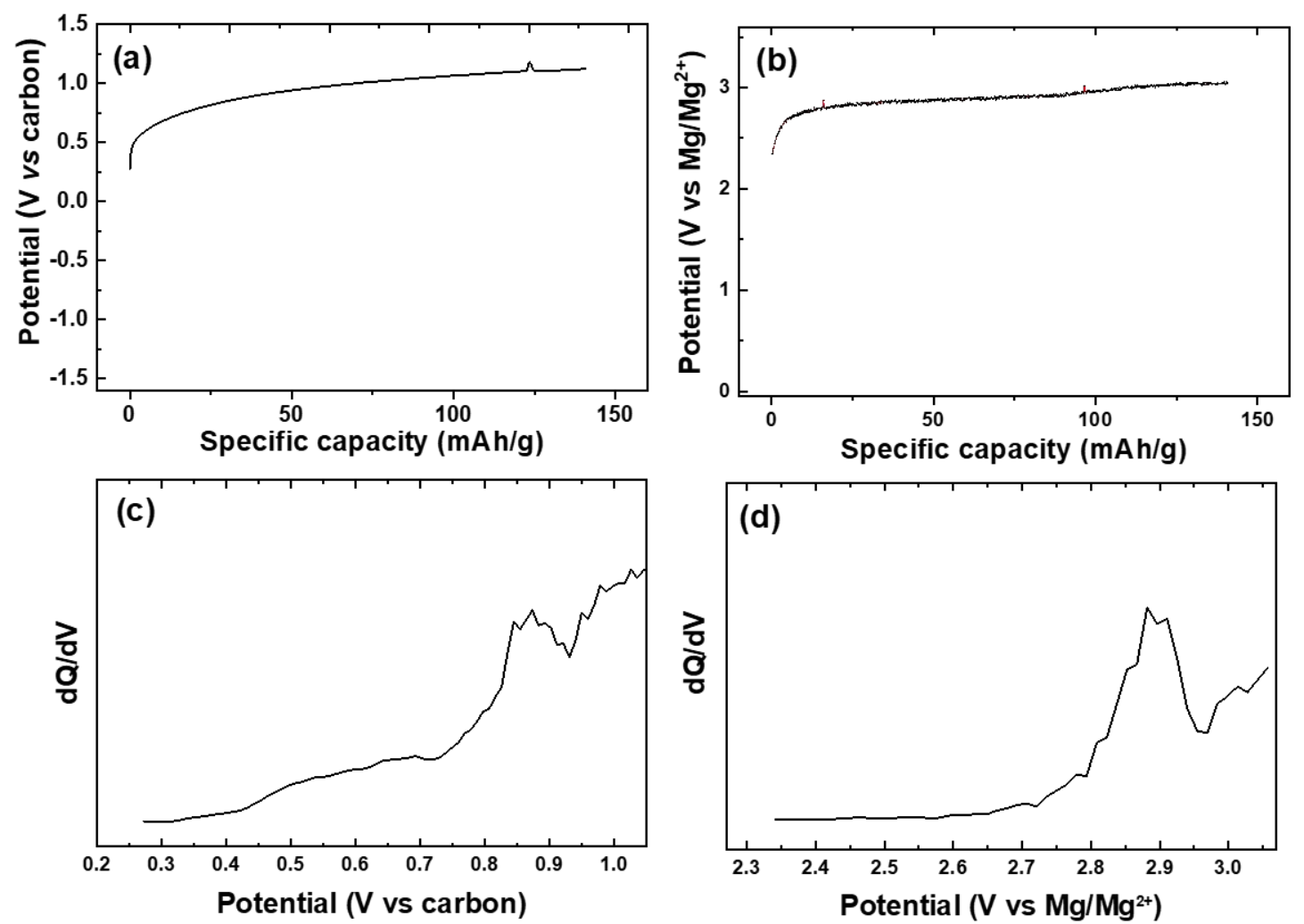

Figure S19. Potential versus capacity profiles of $\mathrm{MgCrMnO}_{4}$ in a (a) half-cell and (b) full-cell at $95{ }^{\circ} \mathrm{C}$. The corresponding $d \mathrm{Q} / d \mathrm{~V}$ plots of anodic reaction in a (c) half-cell and (d) full-cell. 


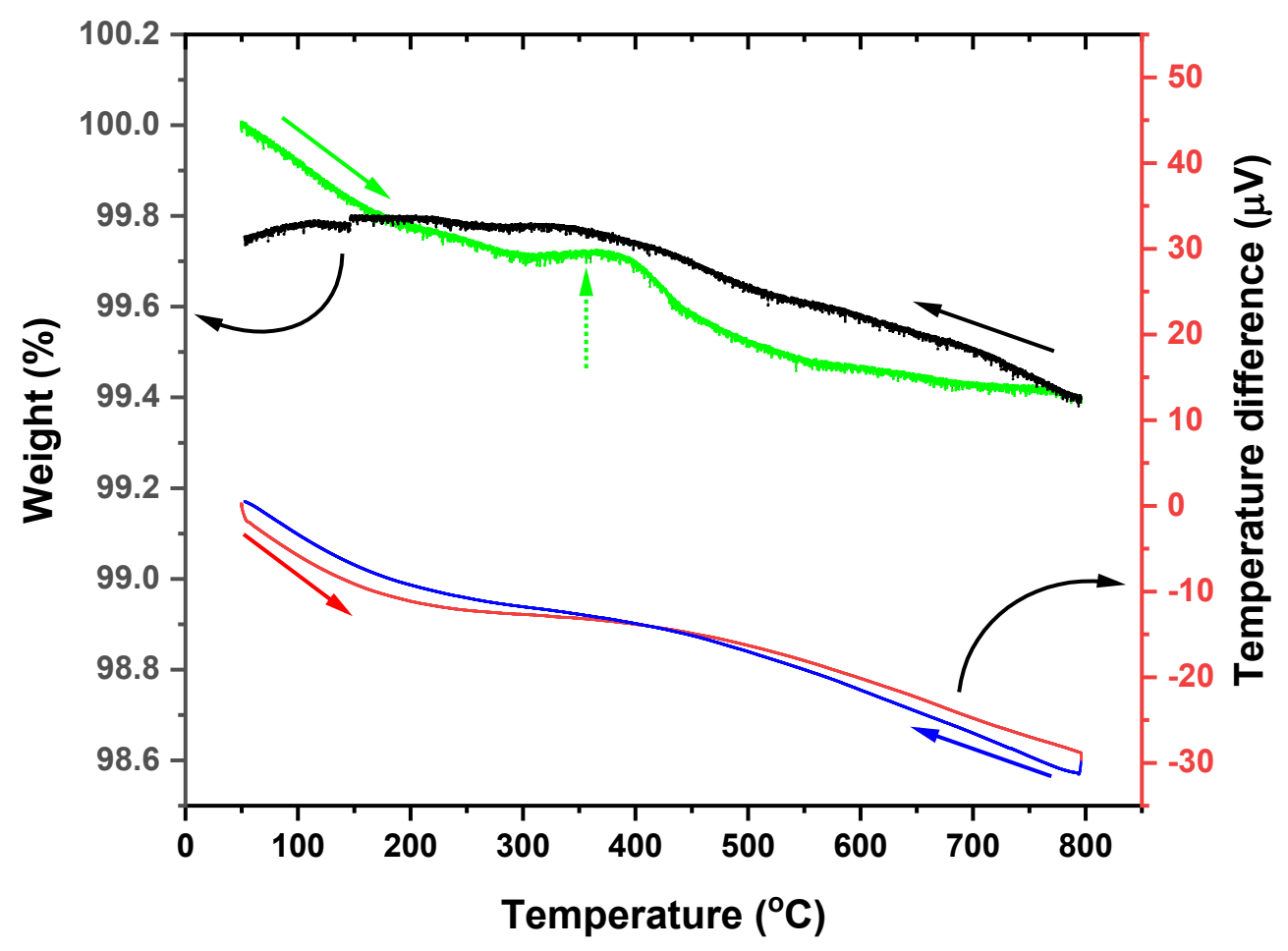

Figure S20.Thermal gravimetric analysis of pristine $\mathrm{MgCrMnO}_{4}$. 


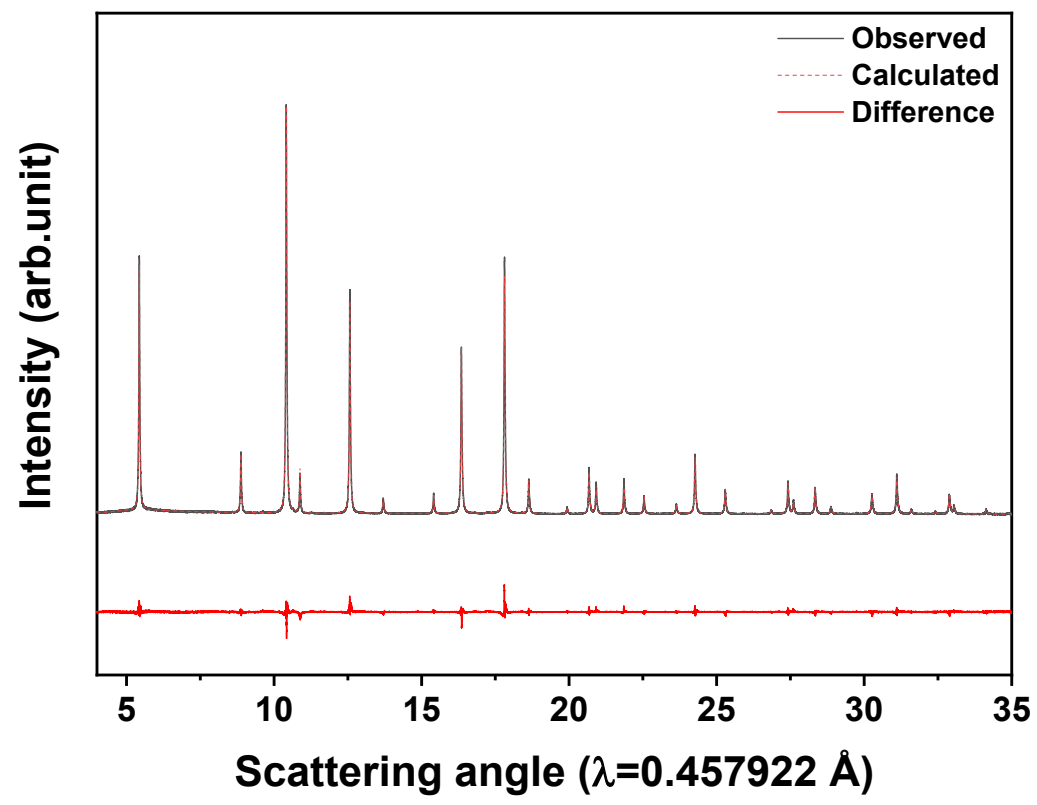

Figure S21. Synchrotron XRD data Rietveld refinements of post- $\mathrm{MgCrMnO}_{4}$ annealed at 350 ${ }^{\circ} \mathrm{C}$ for 24 hours in air. 

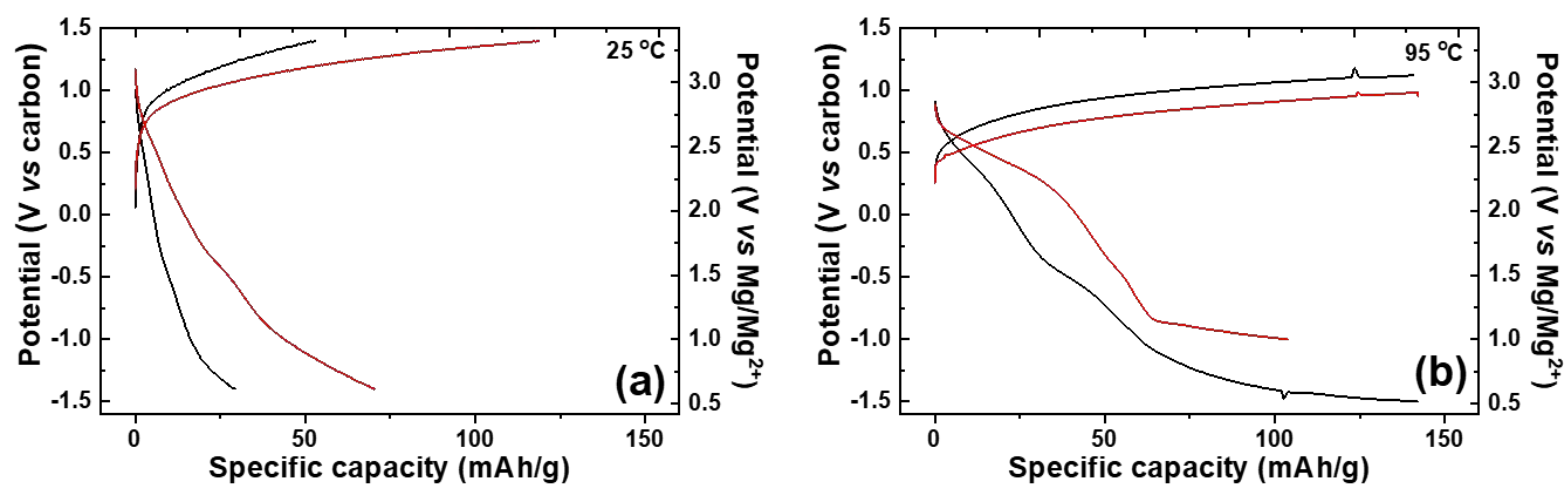

Figure S22. Representative potential versus capacity profiles of $\mathrm{MgCrMnO}_{4}$ (black) and post$\mathrm{MgCrMnO}_{4}$ (red) at (a) $25{ }^{\circ} \mathrm{C}$ and (b) $95{ }^{\circ} \mathrm{C}$ paired with a carbon counter electrode. 


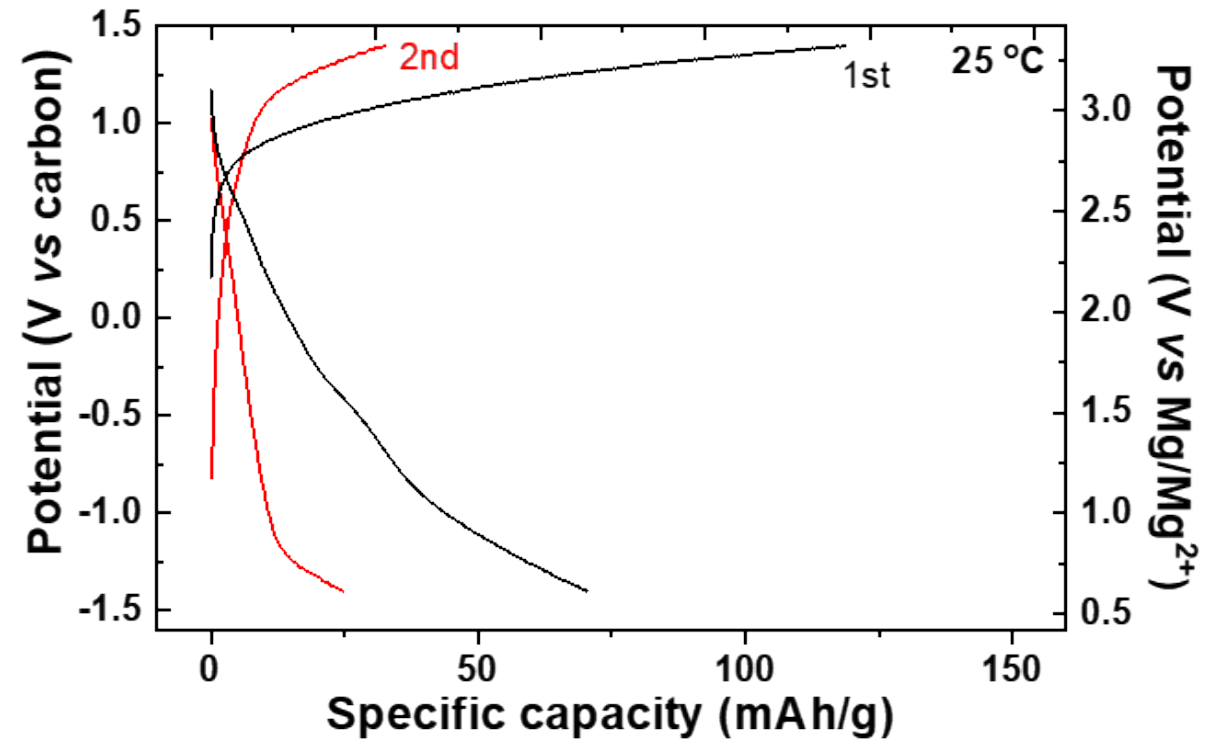

Figure S23. Representative potential versus capacity profiles of post- $\mathrm{MgCrMnO}_{4}$ at $25^{\circ} \mathrm{C}$ paired with a carbon counter electrode. (Black: $1^{\text {st }}$ cycle and red: $2^{\text {nd }}$ cycle) 


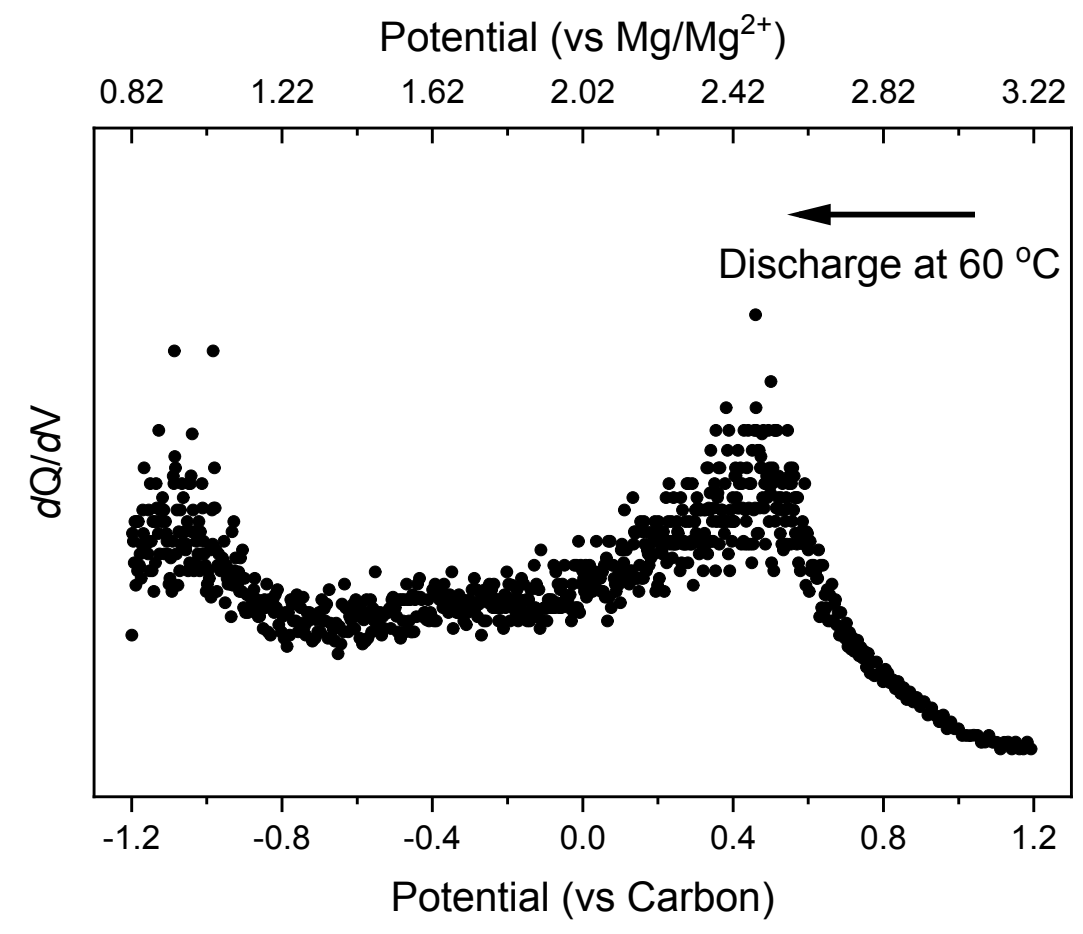

Figure S24. An incremental capacity plot of cathodic reaction in a half-cell containing post$\mathrm{MgCrMnO}_{4}$ working electrode cycled at $60^{\circ} \mathrm{C}$. 


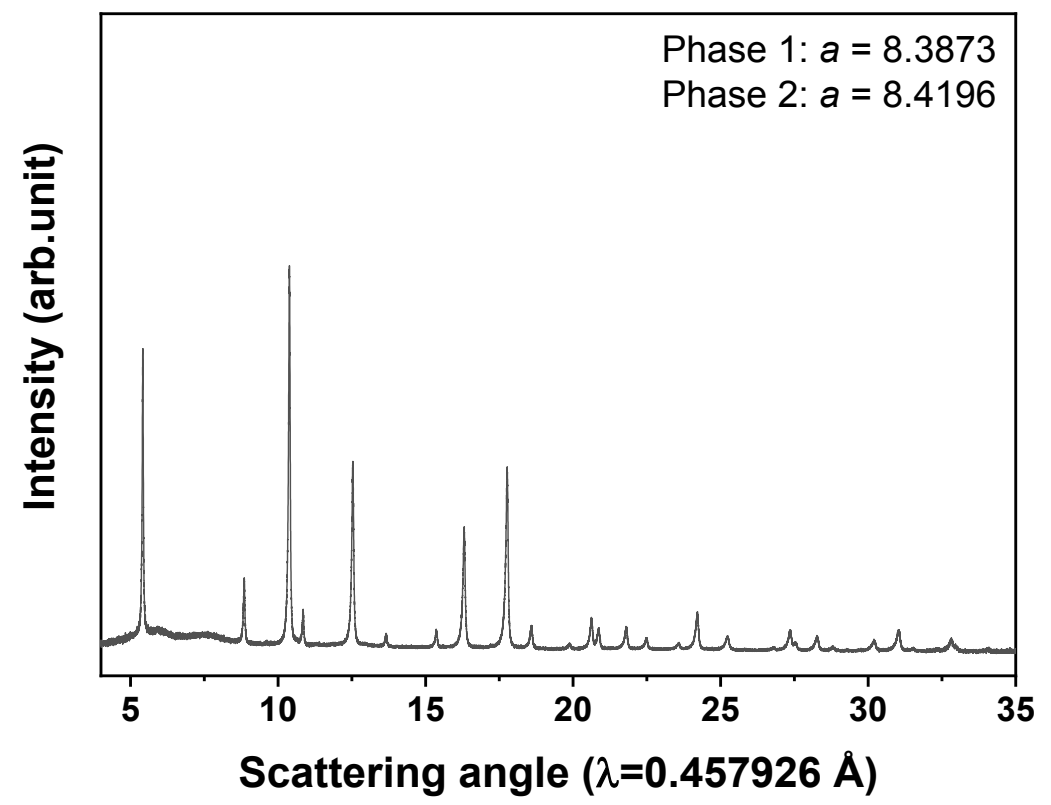

Figure S25. Synchrotron XRD pattern of the electrode after 50 cycles at $60{ }^{\circ} \mathrm{C}$. 